\title{
Hypericum androsaemum L. (Clusiaceae [=Guttiferae]), novedad corológica para la provincia de Córdoba (Andalucía, España)
}

\author{
Javier López Tirado \\ Departamento de Ciencias Integradas. Facultad de Ciencias Experimentales, \\ Campus de El Carmen, Universidad de Huelva, 21071 (Huelva).
}

\author{
Correspondencia \\ J. López Tirado \\ e-mail: javier.lopez@dbasp.uhu.es \\ Recibido: 31 julio 2017 \\ Aceptado: 6 noviembre 2017 \\ Publicado on-line: diciembre 2017
}

\begin{abstract}
Hypericum androsaemum L. (Clusiaceae [=Guttiferae]), new record for Cordoba province (Andalusia, Spain)
\end{abstract}

Palabras clave: Corología, Clusiaceae, Guttiferae, Hypericum androsaemum, novedad, Córdoba.

Key words: Chorology, Clusiaceae, Guttiferae, Hypericum androsaemum, new record, Cordoba.
Hypericum androsaemum L. es una liana perennifolia fanerofítica propia de zonas umbrosas, frescas y con cierto grado de humedad (Ramos Núñez, 1993). Su presencia en la Península Ibérica se hace más patente mientras más hacia el norte. Es especialmente frecuente en áreas pertenecientes a la región eurosiberiana, encontrando continuidad hacia el centro de Portugal y adentrándose en España por el sur de Castilla y León, norte de Extremadura y oeste de Castilla-La Mancha. La zona norte del Levante peninsular (hasta la provincia de Castellón) también alberga a este taxón (www.anthos.es, flora-on.pt y www.gbif.org). En Andalucía se dudaba de su presencia en la Sierra Morena jiennense y en las Sierras de Algeciras (Cádiz) según Ramos Núñez (1993), aunque existían datos de esta especie en inventarios fitosociológicos de los años 60 (cfr. Pérez Latorre et al., 1996). Son estos últimos autores los que citan por primera vez con pliego de herbario a $H$. androsaemum en Andalucía, concretamente en el Valle del río Genal, Puerto de los Guardas (provincia de Málaga). En el caso de la localidad de Jaén, esta se encuentra en el término municipal de Andújar, próximo al arroyo de Navidad (Molina Moreno et al., 1994). Más recientemente, Morales Torres (2009) confirma esta especie para la Sierra Morena jiennense y para el Aljibe de la provincia de Málaga.

La especie objeto de esta nota se ha recolectado en la provincia de Córdoba, lo que supone novedad corológica para la misma y amplía su escasa distribución en Andalucía. Un pliego testigo ha sido depositado en el Herbario del Real Jardín Botánico de Córdoba (COA).

\section{Hypericum androsaemum $\mathrm{L}$.}

CÓRDOBA. Obejo: Bajando del pico Puntales [30SUH4914], 500 m, 24.VII.2016, J. López Tirado (COA 57927).

El hábitat donde se ha encontrado ha sido una vaguada con orientación norte que en el momento de la recolección (finales del mes de julio) tenía agua y estaba acompañada de especies tales como Rubus ulmifolius Schott, Myrtus communis L., Carex pendula Huds. y Cistus albidus L. Este hábitat coincide con aquel encontrado en las otras dos localidades andaluzas. La nueva localidad tiene las poblaciones más cercanas en Sierra Madrona (Ciudad Real) (Martín-Blanco \& Carrasco, 2005; García Río, 2006) y sirve para ampliar la distribución de $H$. androsaemum en Sierra Morena oriental, provincias de Ciudad Real, Córdoba y Jaén (subsector Marianense). Sería interesante hacer un seguimiento y evaluación de las poblaciones a nivel autonómico, donde se incluyese un conteo de individuos y poblaciones, para poner en conocimiento su estado de conservación.

\section{Referencias}

ANTHOS (2017). Sistema de Información de las Plantas de España. Real Jardín Botánico, CSIC - Fundación Biodiversidad. Fuente electrónica en www.anthos.es. 
Último acceso en julio de 2017.

FLORA-ON (2017). Flora de Portugal Interactiva. Sociedade Portuguesa de Botânica. Fuente electrónica en www.flora-on.pt. Último acceso en julio de 2017.

García Río, R. (2006). Flora y vegetación de Sierra Madrona y Valle de Alcudia. Bases científicas para su conservación. Centro de Investigaciones Ambientales del Mediterráneo.

GBIF -2017- Global Biodiversity Information Facility. Fuente electrónica en www.gbif.org. Último acceso en octubre de 2017.

Martín-Blanco, C.J. \& Carrasco, M.A. (2005) Catálogo de la flora vascular de la provincia de Ciudad Real. Monograf. de la AHIM, vol 1.
Molina Moreno, J.R., Mancebo Quintana, J.M. \& Gómez Manzaneque, F. (1994) Fragmenta chorologica occidentalia, 5129-5156. Anales Jard. Bot. Madrid, 52(1), 93-94.

Morales Torres, C. -2009- Clusiaceae (=Guttiferae) in Blanca, G., B. Cabezudo, M. Cueto, C. Fernández López \& C. Morales Torres (eds.) Flora Vascular de Andalucía Oriental, 2, 285-291. Consejería de Medio Ambiente, Junta de Andalucía, Sevilla.

Pérez Latorre, A.V., Cabezudo, B. \& Nieto Caldera, J.M. (1996). Sobre la presencia de Hypericum androsaemum L. en Andalucía. Lazaroa, 17, 157-159.

Ramos Núñez, Á.F. (1993). Hypericum L. in Castroviejo, S. et al. (eds.) Flora Iberica vol. III: 157-185. C.S.I.C., Madrid. 